\title{
¿Construir al Estado o al ciudadano? Aproximación a las ideas de Pedro de Angelis sobre la organización política argentina, 1827-1856
}

\author{
Fernando Carlos Urquiza \\ UNIVERSIDAD NACIONAL DEL CENTRO \\ DE I.A PROVINCIA DE BUENOS AIRES
}

\begin{abstract}
En este trabajo se realiza un acercamiento a las ideas de Pedro de Angelis sobre la organización política que debía reemplazar al Estado colonial tras el proceso emancipador en el Río de la Plata, que culminó con la sanción de la Constitución de 1853.
\end{abstract}

\section{INTRODUCCIÓN}

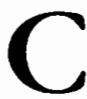

uando intentamos un balance de la historia de los intelectuales del Río de la Plata desde principios del siglo XIX son muchas las figuras que se hacen presentes. Cada una se asocia indefectiblemente a sus aportes, sean éstos de índole artística, política, filosófica o educativa. Sin embargo, hay una figura que destaca además por los polémicos juicios -surgidos de su actuación al servicio de bandos opuestos- que ha desatado a la hora de decidir cuál es el lugar que debe ocupar en la historia argentina.
Nos referimos a Pedro de Angelis, escritor napolitano de dilatada actuación -como periodista, educador e historiador- en Buenos Aires.

El objetivo de nuestro trabajo es, alejándonos de los aspectos polémicos de la figura de De Angelis, abordar el pensamiento político en general del napolitano; es decir, analizaremos sus conceptos acerca del Estado, la sociedad y el sistema político rioplatense expresados a través de su obra escrita. Hemos evitado la tentación de detenernos en su etapa de ideas unitarias o de aquélla en que asistió intelectualmente al Rosas, para analizar su pro- 
ducción como una unidad y tratar de ver en ella las principales líneas de reflexión, analizando a la vez, su evolución.

Es necesario tener en cuenta que en la región, desde 1810 , comenzó el proceso de desestructuración del Estado colonial y se inició el debate sobre la forma que debería tener el Estado que lo reemplazaría. En esa época, dos conflictos le imprimen el ritmo a los acontecimientos y caracterizan el curso de los sucesos políticos: el primero, podríamos sintetizarlo como un centralismo-anticentralismo, que surge ya en 1810 cuando Buenos Aires - luego del establecimiento de la Primera Junta de Gobierno- intenta imponer su autoridad al resto de las ciudades del antiguo virreinato; el otro es el conflicto que enfrenta a Unitarios y Federales y que expresa en parte, y de manera muy imperfecta, al anterior sin que pueda proponerse una identificación entre federales y anticentralistas.

La década de 1810-1820 registró avances y retrocesos en cada uno de los polos de los antagonismos mencionados, que se manifiestan en la sucesión de diversas formas de gobierno - como la Primera Junta, la Junta Grande, el Primero y Segundo Triunviratos y el Directorio- en la región. A partir de 1820 , con la caída de las autoridades centrales en el territorio, parecen triunfar quienes se oponen a la preeminencia de Buenos Aires y apoyan las ideas federales; sin embargo, es necesario dejar en claro que la derrota temporal de los unitarios permite a Buenos Aires iniciar una nueva fase en su desarrollo económico que, en pocos años, posibilitará a Juan Manuel de Rosas -gobernador de la Provincia, defensor del federalismo y encargado de las Relaciones Exteriores de la Confederación- ejercer un evidente centralismo desde Buenos Aires sobre el resto de las provincias gobernadas por caudillos federales.

En ese periodo fracasan varios intentos de sancionar una constitución que organice a las Provincias Unidas del Río de la Plata -unidas mediante pactos regionales - en forma definitiva. El dilema al que debieron enfrentarse los diputados constituyentes representantes de las provincias era si debían consagrar o no, en el texto constitucional, redactando una carta unitaria o federal, la superioridad de Buenos Aires. A pesar de que su posición de privilegio le era disputada por otras ciudades del interior, también es cierto que éstas no lograron imponerse sobre la ciudad del puerto; es así que, de 1810 a 1853 los bandos en pugna no pudieron formar consenso ni imponer una organización -ya fuera unitaria o federal- dado que el poderío político y militar de cada uno sólo bastaba para impugnar los planes institucionales de sus oponentes pero no para llevar a cabo los propios. Sin embargo, es importante señalar que, a pesar de los intentos de reunión de congresos constituyentes en ciudades rivales de Buenos Aires - como La Rioja o Córdoba- la palabra constitución terminó siendo, en aquella época, sinónimo de unitarismo, proceso de cambio de significados casi natural, dada la importancia que los unitarios otorgaban a la sanción de una carta magna. En lo que respecta al conflicto centra- 
lismo-anticentralismo, existe consenso entre los historiadores en pensar -y los hechos así lo indican - que la balanza se inclinó en favor de los primeros; una evidencia en este sentido es el control que el gobernador de Buenos Aires ejerció, por diversos medios, sobre todo el territorio.

En 1852 se produjo la caída de Rosas debido a un enfrentamiento con Urquiza - un caudillo del interior, antiguo aliado de Rosas cuya función fue reprimir los levantamientos antirrosistas del litoral para lo cual contó con un poderoso ejército, y que se vio perjudicado, del mismo modo que Brasil, Paraguay y Corrientes, por la negativa del caudillo porteño a permitir la libre navegación de los ríos dando inicio a una etapa que la historiografia nacional ha denominado "época de la Organización Nacional". En ese periodo se sancionó una constitución -redactada según los lineamientos presentados por Juan Bautista Alberdi en su obra Bases y puntos de partida para la organización política de la Re. pública Argentina de carácter federal centralista, en la que a las potestades provinciales se superpone una potestad superior, que es el Estado nacional. De ese modo, los conflictos antes mencionados -centralismo-anticentralismo, por un lado, y federales-unitarios, por otro- encuentran una solución en la que se reconoce la preeminencia del puerto en el marco de una organización institucional federal.

Éstas son, presentadas en forma muy resumida, las principales características del periodo histórico en que Pedro de Angelis desarrolló sus actividades como intelectual en el Río de la Plata.
En cuanto a sus datos biográficos, éstos se repiten de un autor a otro, pero pese a haber sido tan divulgados nos parece importante incluirlos aquí porque ofrecen una visión de la formación intelectual y política de nuestro personaje, además de mostrarnos los escenarios en que habitualmente desarrolló sus acciones.

De Angelis nació en Nápoles en 1784; a raíz de su esmerada educación, se convirtió en pedagogo de los hijos del rey Murat, impuesto por Napoleón en el sur de Italia. Residió como ministro del rey en San Petersburgo y luego ingresó como profesor en la Real Escuela Politécnica y Militar. A la caída de Napoleón se trasladó a París en misión oficial y se convirtió en uno de los redactores de la Biographie Universelle Ancianne et Moderne. Fue también oficial de artillería y corrector de la tipografía, adjunto al estado mayor del ejército. Cultivó la amistad de importantes personajes de la época como el general Lafayette, Destutt de Tracy, el conde Orloff, Michelet y Sismondi, entre otros.

Llegó al Río de la Plata en 1827 después de haber conocido, probablemente en 1824, en París-a Bernardino Rivadavia. Lo acompañaba su mujer Melanie Dayet, quien más adelante fundaría una escuela para señoritas. En esta etapa de servicio a Rivadavia actuó junto a José Joaquín de Mora, con quien dirigió dos periódicos. $L a$ Crónica Política y Literaria de Buenos Aires y El conciliador. En 1829 lanzó El Lucero y una publicación en francés: Laflaneurambigu,politique et litéraire.

Durante su etapa federal editó $E l$ 


\section{SECUENCIA}

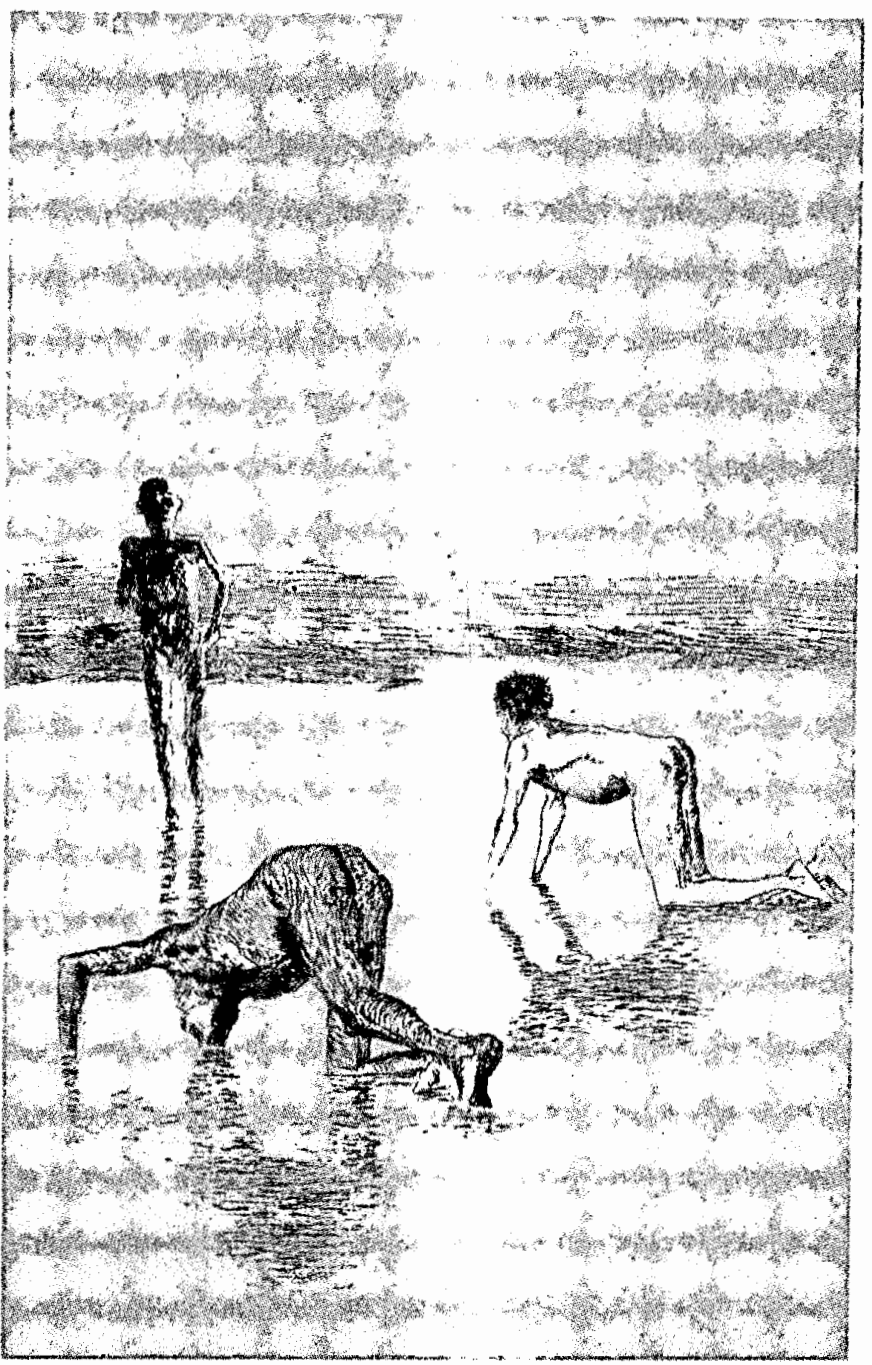

Grabados del Taller Tiempo Extra Editores. Fotografía de Mónica Velasco.

Queda estrictamente prohibida la reproducción total o parcial

de las imágenes publicadas en este número de la revista Secuencia, 36.

Las imágenes fueron contratadas y/o donadas de forma exclusiva para esta publicación. 
Restaurador de las Leyes y posteriormente se sumó a La Gaceta Mercan$t i l$, que continuaba apareciendo desde 1823 , ahora redactada por Nicolás Mariño y José Rivera Indarte, entre otros. Pero quizá el más importante periódico impulsado por De Angelis en esta época fue Archivo Americano y Espíritu de la Prensa del Mundo, publicado en tres idiomas -castellano, inglés y francés-y cuyo objetivo era dar la visión oficial de los sucesos del Río de la Plata en Europa.

Nos ha resultado interesante el modo en que los diversos autores han tratado la obra de De Angelis. Son varios Ios ángulos desde los que se ha estudiado el tema: desde lo político ideológico hasta lo intelectual, pasando por lo periodístico. En este último caso, C. Galván Moreno, ${ }^{1}$ luego de hacer una brevísima reseña de los periódicos aparecidos y desaparecidos durante la época de Rosas - tomando como fuente la obra de Zinny-concluye que la política restrictiva del gobernador en cuanto a publicaciones condena a muerte a la prensa porteña. Sólo rescata a The British Packet, La Gaceta Mercantil, Archivo Americano -cuya misión es alabar a Rosas-y el Diario de la Tarde, dos de los cuales eran redactados por De Angelis, asentando así su pericia para estas tareas.

José María Ramos Mejia, ${ }^{2}$ por su parte, opina que De Angelis fue director de cierto tipo de elevada propaganda en favor de Rosas que otros secuaces del gobernador no podrían ha-

1 Galván, Periodismo, 1942, cap. XIII.

${ }^{2}$ Ramos, Rosas, 1944, cap. $\mathrm{x}$. ber realizado. No hubo cuestión aquí -según el parecer de Ramos Mejíaque no fuera tratada a fondo y con brillo por De Angelis. Ricardo Rojas, en su Historia de la literatura argenti$n a,{ }^{3}$ propone un acercamiento más comprensivo de la figura del italiano y analiza su obra desde la perspectiva literaria, a partir de su desembarco hasta su muerte. Contrariamente a Ramos Mejia, cree que la producción más importante de De Angelis no es la periodística sino la histórica, señalando su Colección de documentos para la historia del Río de la Plata como el máximo exponente de su labor y el mayor acontecimiento bibliográfico durante la dictadura rosista.

Rodolfo Trostiñé, en el prólogo a una obra compilada por él mismo, ${ }^{4}$ hace una análisis en el que profundiza en la actuación de De Angelis segmentando por rubros el material documental. Así, en su artículo titulado "Pedro De Angelis y la cultura" nos habla de la labor periodística, los trabajos historiográficos, los estudios de las lenguas indígenas, laactividad educadora, las polémicas y las relaciones del napolitano con Rosas y Urquiza, haciendo una serie de evaluaciones particulares sobre sus aportes. Las conclusiones son similares a las de otros autores aunque De Angelis es tratado con mayor benevolencia; le censura su acrítica adhesión a Rosas pero resalta y valora el resto de sus contribuciones a la cultura de la sociedad porteña.

Otro artículo que completa la obra

\footnotetext{
3 Rojas, Historia, 1960, vol. 6, cap. IV.

4 Trostiñé, Acusación, 1945, prólogo.
} 
del citado autor y que pertenece a Enrique de Gandía versa específicamente sobre las ideas políticas de De Angelis. Comprende todas las etapas por las que atravesó y lo enjuicia desde una perspectiva antirrevisionista. Como es de esperarse, De Gandía no logra -a pesar de lo minucioso de su trabajo y la amplia documentación consultada-llevar más lejos que otros autores sus conclusiones; sólo su juicio en cuanto a las ideas es diferente: le critica haber abandonado la causa unitaria y haberse puesto al servicio de Juan Manuel de Rosas, a quien por supuesto califica de tirano.

Parece bastante claro, según puede inferirse de esta breve reseña, que la estatura intelectual de De Angelis está fuera de duda, aunque pueda discutirse si sus mayores aciertos están en el periodismo, la literatura, la educación o la política. Existe también un acuerdo básico sobre las críticas al napolitano en torno a sus pronunciados giros políticos, que van desde brindar sus servicios a Rivadavia hasta ofrecérselos a Urquiza, pasando por una dilatada etapa de trabajo a las órdenes de Rosas.

Por nuestra parte, creemos necesario hacer hincapié en que el napolitano parece ser una figura sumamente respetada por otros intelectuales que actuaron en la misma época. En este sentido, es preciso mencionarque parece confirmada su presencia - que obedecía a una invitación previa-en el Salón Literario durante la inauguración de la Asociación de Mayo, presidida por Esteban Echeverría. También consta el continuo intercambio de libros y la existencia de relaciones cordiales en- tre ambos - a pesar de sus opiniones dispares-, lo que no les impidió mantener un debate público sobre el Dogma Socialista.

De toda la obra de De Angelis, los escritos con mayor contenido político-ideológico son sus Ensayos literarios y políticos, publicados en 1833 y surgidos de una recopilación de los artículos periodísticos producidos entre 1827 y 1833 , y sus notas publicadas en Archivo Americano que, engeneral, tratan sobre diversos aspectos de la gestión de Rosas y realizan una defensa de ésta. En la primera podríamos decir que se resume la etapa de su pensamiento unitario, expresado mediante apuntes aparecidos en la prensa y cuyo objetivo era la exposición de las ideas "correctas" que, desde su punto de vista, convenían al territorio en ese momento. El entrecomillado se debe a que, en general, hay aquí un desarrollo didáctico y razonado de los temas, de modo que las conclusiones se desprenden -de forma inapelable, podríamos decir-de las premisas. Estas apreciaciones se complementan con las de otros autores, también unitarios, que abordan análisis de estilos estéticos en general -sobre todo desde el punto de vista literario- sin que falte por esta causa la opinión política.

En Archivo Americano, en cambio, su desempeño parece ser diferente. En efecto, quizá hay en estos temas menos exposición de tipo magistral y aparece una mayor discusión de ideas dado que la mayoria de sus artículos son respuesta a críticas al régimen rosista aparecidas en la prensa extranjera. En esta etapa, el punto de partida es diferente ya que debía tener en cuenta 
los argumentos de su oponente y -esto lo señalan varios autores- su respuesta debía satisfacer a Rosas, quien lé́a y comentaba todos los escritos de De Angelis. Por este motivo, es necesario insistir en que las ideas expuestas aquí surgen a la luz de un debate con los opositores y con el propio Rosas, lo que le confiere a los textos del napolitano un matiz propagandístico presente aunque velado en la etapa anterior de su producción.

Finalmente, hay un documento más que expresa las ideas de nuestro personaje luego de la caída de Rosas. Se trata de un proyecto de constitución nacional que De Angelis envió a Urquiza - quien provocó la caída de Rosas- luego de que éste convocara a un Congreso constituyente. Este proyecto no fue discutido en la Cámara, y aunque se desconoce la causa puntual que motivó este olvido, diversos historiadores coinciden en afirmar que fue el desprestigio político en que había caído su autor en esa época.

Estas tres obras -los Ensayos literarios y políticos, los artículos aparecidos en Archivo Americano y el proyecto de constitución - han sido la base fundamental y las fuentes básicas del presente trabajo.

LAS IDEAS POLITICAS DE DE ANGELIS ANTES DE LA LLEGADA DE ROSAS

\section{AL PODER}

En un artículo que forma parte de los Ensayos literarios y políticos analiza las relaciones entre libertad, Constitución y extremismo político. Al respecto dice:

¿Construir al Estado o al ciudadano?
Una libertad moderada es propia de los pueblos cultos, y el término de sus es. peranzas. Los desmanes no aprovechan ni aun a los que los promueven porque las naciones no se detienen jamás en el camino de la anarquía y tarde o temprano se vengan de los que las han extraviado. 5

Afirma que hay numerosos ejemplos históricos que confirman esta máxima, y con tal fin cita a Robespierre:

No vengan a hablarnos de Constitución -decía [Robespierre]-, demasiado nos ha adormecido esta palabra. La Constitución no es más que un libro: ¿y qué importa un libro cuando no hay libertad?" A lo cual De Angelis agrega: "Continuamente oímos hablar en el mismo sentido y lo que más nos asusta es que así preparó Robespierre el reinado del terror [...]. Pero tantos crímenes no podían quedar impunes y fueron expiados por los mismos medios que habian servido a su ejecución", concluyendo que "lo más importante es precaverse contra la exaltación en los negocios públicos. En todo hay un medio, y aun en las cosas que más de cerca nos tocan. Todo exceso es vicioso y los pueblos se cansan tanto de una completa servidumbre como de una libertad desenfrenada" ${ }^{6}$

Parece bastante claro que en este análisis del escenario político rioplatense De Angelis asigna a la Constitución -una especie de ley máxima consensual que fije las reglas del juego-el papel de reguladora de la libertad, a quienes luchan por imponerla el papel de libertarios moderados -los ver-

\footnotetext{
5 Ibid., p. 243.
}

${ }^{6}$ Ibid., p. 245. 
daderos libertarios, en su concepcióny a los federales reticentes a aceptar su sanción, el papel de libertarios desenfrenados. Esta libertad moderada, que incluye la libertad de imprenta ilimitada, sería el único remedio contra tiranos y charlatanes carismáticos que extravian a la muchedumbre. Al respecto opina:

Raras veces sucede que su imperio se prolongue en un país que goza de la libertad de imprenta. Ilustrar al pueblo es el verdadero modo de enseñarle a consultar sus intereses reales y a huir de las pérfidas sugestiones de sus enemigos. $^{7}$

En un artículo titulado "Reflexiones políticas" introduce una idea, que podría compararse con la noción de "unión sagrada", ante el enfrentamiento con el imperio de Brasil y la utiliza como un motivo más para aceptar la Constitución. Abona su razonamiento con el ejemplo de la Francia revolucionaria a la que todos se sumaron bajo la bandera republicana para defender la patria. En Río de la Plata, por el contrario, los "buenos patriotas" ven mezclarse las alegrías por las victorias exteriores con las tristezas de los avances de la guerra civil.

¿Así se sirve a la causa de la libertad?, ¿así se merece la gratitud de la patria?, ihabremos sacudido el yugo de nuestros opresores para fomentar odios y perpetuar rencores? [...]. De nada sirve declararnos contra la monarquía, y haber derrocado al despotismo si no se piensa en poner los cimientos de una

7 Ibid., p. 246. sabia y prudente libertad. Cuántas veces se nos ha brindado con una Constitución y otras tantas la hemos rechazado. Estos ensayos, a pesar de sus defectos, hubieran contribuido a preservarnos del desorden, en tanto que la mano del tiempo les hubiera dado la perfección que los hombres no pueden imprimir de pronto a sus obras. ${ }^{8}$

De Angelis cierra su análisis con las benéficas consecuencias que podría haber traído una constitución y una paz interna derivada de ella:

Cuánto ha que hubiéramos podido consolidar nuestra existencia por medio de leyes justas, reclamadas por los intereses generales: y entre tanto nuestros magistrados están aún en la humillante obligación de consultar la Recopilación de Indias y las Ordenanzas de Bilbao para pronunciar sus fallos, que quizás nos parecerían injustos si tuviésemos un código nacional $[. .$.$] ¿Queréis$ que el pueblo ame y defienda su libertad para que fije su atención en estos objetos? ¿Queréis levantar un edificio que no puede levantarse sino por un procedimiento lento y pacífico, y estáis sacudiendo continuamente lodo??

En una nota aparecida en la prensa porteña en 1827, en la que analiza el porvenir de Brasil, desliza sucintamente su concepto de federalismo y las críticas de su aplicación en América del Sur. Comienza su estudio recorriendo la historia y demostrando que cuando una revolución se produce en una gran unidad política, suelen surgir múltiples pueblos determinados por

8 Ibid., p. 251.

${ }^{9}$ Ibid., p. 252. 
condiciones geográficas, vínculos morales y mercantiles, costumbres, etc. Un poder superior a cada uno de los pueblos puede mitigar por un tiempo todas las fuerzas centrífugas, pero en definitiva su disgregación es inevitable; sin embargo, una excepción a esto son los imperios coloniales, que pueden mantenerse indefinidamente siempre que las metrópolis sean capaces de otorgar ciertas concesiones. Éste es, según el autor, el caso de Brasil, una colonia separatista a la que se le ha dado la concesión de la libertad a cambio de conservar la dinastía en el gobierno.

A continuación, De Angelis realiza un análisis de sus condiciones geográficas haciendo hincapié en la inmensidad de su territorio, el aislamiento de algunas de sus regiones y la escasez de sus vías de comunicación. Luego se pregunta: " $¿ Q u e ́$ vínculos pueden tener entre sí zonas tan heterogéneas? ¿Cómo puede formarse una familia con individuos que ni se conocen?", y concluye que "los brasileros sólo pueden formar un cuerpo mientras vivan sometidos a un yugo". ${ }^{10}$

La lectura del texto sugiere que sólo dos caminos le quedan al imperio brasileño; por un lado, una fragmentación regional-similar a la ocurrida con las colonias españolas- producto de las fuerzas centrífugas que anidan en su espacio geográfico o, por el otro, una unidad más o menos ficticia que convertiría el escenario político en campo de batalla de partidos y personajes ambiciosos. Esta última posibilidad sería nefasta para el imperio ya que sólo la

${ }^{10}$ Ibid., p. 255. paz y el reposo en los diversos estados que lo componen son la fuente exclusiva de prosperidad y bienestar.

Acerca de las posibles soluciones, y profundizando en el tema que nos ocupa, opina:

No se crea que una federación bastaría para paliar semejantes males. El sistema federativo, del que generalmente se habla sin comprenderlo, supone una civilización adelantada en todos los estados que la componen; una población numerosa y con frecuentes medios de comunicación; un equilibrio perfecto de poderes supremos y subalternos, que sólo se adquiere en la práctica de instituciones libres; un pueblo al fin acostumbrado a tomar parte en las decisiones relativas a sus intereses e iniciado en todos los ramos de la existencia política. El tránsito de la esclavitud más humillante a la libertad exige algún aprendizaje de parte de los pueblos; sobre todo cuando alentados por las victorias sobre un poder injusto, les cuesta trabajo doblegarse ante el yugo de la ley. Cómo es .posible esperar una federación bien ordenada en un pueblo como el del Brasil que, por desgracia, apenas posee los elementos de la civilización. ${ }^{11}$

De Angelis, a través de la comparación del imperio portugués con el imperio español, predice un futuro similar para ambos; una fragmentación política producto de las condiciones imperantes en cada región. Una posibilidad para mantener la unión de las colonias lusitanas en América es la aplicación de un sistema federativo, pero según el autor para que esta solución tenga éxito son necesarias varias

${ }^{11}$ Ibid., p. 257. 


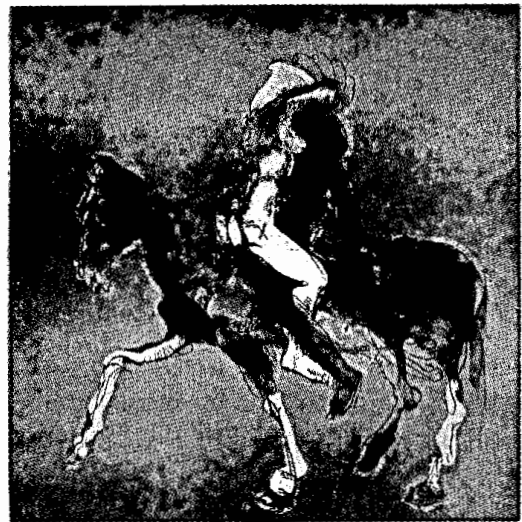

condiciones que en su opinión no reúnen. Dichas condiciones podrían resumirse en que para que el federalismo sea viable es necesaria una larga práctica en el marco de instituciones libres; hasta que esto se logre no hay otra posibilidad más que imponer el yugo de la ley. Es interesante recordar aquí que, para De Angelis, la práctica política debe ser moderada por la ley y ésta es sinónimo de Constitución; en otras palabras, los pueblos nuevos deben someterse al yugo de la Constitución hasta lograr un aprendizaje que les permita vivir bajo un sistema federal.

Esta afirmación resulta interesante porque con ella podríamos establecer, sin temor a forzar los hechos, un paralelismo con las preocupaciones que va a manifestar Alexis de Tocque ville, años después, en La democracia en América. Tanto De Angelis como Tocqueville parecen mostrarse preocupados por el futuro de las sociedades en las que viven, si bien el último no se queda sólo con el examen del sistema político, buena parte de su obra está dedicada a este punto. De Angelis entiende -como puede verse en lo anteriormente expuesto-que la ausencia de leyes o, en otras palabras, el exceso de libertad, hace común la existencia de funestos personajes como Robespierre. De modo similar, Tocqueville asegura que el principal peligro de la democracia -sistema social que conjuga igualdad con libertad- es el despotismo, ya que la libertad democrática incita a los hombres a trabajar pensando sólo en sí mismos y a abandonar el control de los negocios públicos. Así pues, para ambos el despotismo se ubica en el pasado, pero advierten que puede haber nuevas formas despóticas en el futuro.

El remedio que recomienda De Angelis para evitar esos males en una sociedad que ha luchado y vencido a la tiranía, cuyas costumbres se han forjado bajo ese sistema político y que aún no se ha acostumbrado a hacer un uso racional de la libertad, es la aplicación de una constitución de la que emane un sistema legal justo. De este modo, la Constitución y las leyes generan en los hombres costumbres que les permiten vivir en libertad; la Constitución crea, con el tiempo, una sociedad con valores y comportamientos democráticos.

Tocqueville encuentra que en América las costumbres democráticas son 
previas al sistema político y que éste es en parte consecuencia de las primeras.

Son, pues, particularmente las costumbres las que hacen a los americanos de los Estados Unidos los únicos entre todos los americanos capaces de soportar el imperio de la democracia; también son las que hacen que las diversas democracias angloamericanas sean más o menos ordenadas y prósperas.

Así pues, se exagera en Europa la influencia que ejerce la posición geográfica del país en la duración de las instituciones democráticas. Se atribuye demasiada importancia a las leyes y muy poca a las costumbres. Estas tres causas ayudan indudablemente a ordenar y dirigir la democracia americana; pero si hubiera que clasificarlas, yo diría que las causas físicas contribuyen menos que las leyes, y las leyes menos que las costumbres. ${ }^{12}$

No obstante, al hablar del espíritu público en Estados Unidos, se pregun. ta cuál es el camino para los pueblos que se hallan en tránsito de una monarquía a una república y cuyas cos. tumbres aún no están lo suficientemente afianzadas como para sustentar una democracia. Es decir, aquellos pueblos que

no tienen el patriotismo instintivo de la monarquía ni el patriotismo reflexivo de la república sino que se han detenido entre los dos, confusos y decepcionados.

¿Qué hacer en semejante estado? Retroceder. Pero los pueblos no recobran nunca los sentimientos de su juventud. [...] Hay que marchar, pues, hacia adelante $y$ apresurarse a hacer que

12 Tocqueville, Democracta, 1984, vol. I, cap. IX, p. 308.

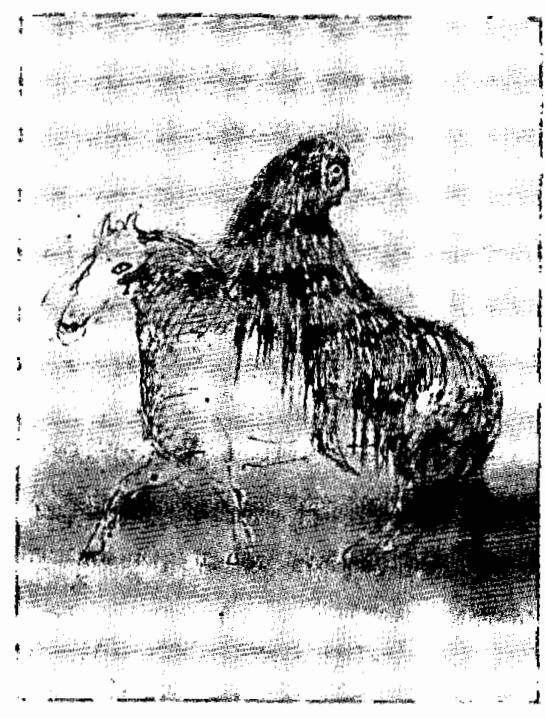

el pueblo vea como una sola cosa el interés individual y el interés del país, pues el amor desinteresado a la patria huye para no volver.

Ciertamente, estoy lejos de creer que para llegar a ese resultado se deba conceder de repente el ejercicio de los derechos políticos a todos los hombres; pero sí opino que el medio más poderoso y quizá el único que nos queda de interesar a los hombres en la suerte de su patria es el de hacerlos participar en su gobierno. Hoy día el espíritu de ciudadanía me parece inseparable del ejercicio de los derechos políticos y creo que en adelante se verá aumentar o disminuir en Europa el número de ciudadanos en proporción a la extensión de estos derechos. ${ }^{13}$

13 De Angelis, citado en Trostiñé, Acusacion, 1945, pp. 237.239. 
El ensayo sociológico de Tocqueville tiene como objeto la sociedad estadunidense, aunque podríamos decir que sus preocupaciones pasan más por Francia que por Estados Unidos, y evidentemente, los problemas de estabilidad e inestabilidad política -entre otros no menos importantes- han ocupado su atención por ese motivo. La cita queda justificada porque su análisis nos resulta muy interesante y podría generalizarse, con ciertos recaudos, para Río de la Plata.

Si nos detenemos a comparar las afirmaciones de Pedro De Angelis con las de Alexis de Tocqueville encontramos que el napolitano presenta ideas que el francés va a desarrollar años después. Así, cuando ambos se refieren a sociedades que salen de una tiranía y buscan un régimen político de libertad, otorgan a las leyes la capacidad de crear nuevas prácticas políticas ajustadas a este sistema que, con el tiempo, se convertirán en costumbres. En otras palabras, un sistema de leyes democrático es capaz de crear -a falta de costumbres republicanas y bajo determinadas condiciones-una sociedad democrática. De las aseveraciones de ambos es posible inferir que, en un principio, estas leyes quizá no sean compartidas por los ciudadanos, pero se hace necesaria su imposición hasta que las costumbres se consoliden y los mismos ciudadanos, ahora habituados a estas prácticas, perfeccionen el sistema legal y político mediante su participación en el ejercicio del poder.

En otro artículo de De Angelis, éste hizo referencia a la tolerancia política. Luego de citar a un autor que no menciona-quien afirma que "la tolerancia del error es la persecución de la verdad"-deduce que la intolerancia autoriza a las más atroces y sanguinarias persecuciones. Asegura que la intolerancia es el único argumento de los que no tienen razón, pues quien la tiene

no teme que el error se presente y combata a cara descubierta, lo deja vivir porque sin duda que él mismo se dará muerte, y en lugar de oponerle los recursos de la violencia y la persecución, se limita a demostrar su mezquindad e inconsecuencia. Tal ha sido en otros tiempos la conducta y divisa de los partidos justos y moderados. ${ }^{14}$

Evidentemente, el mejor medio que tienen para enfrentarse los partidos moderados es el debate público realizado por medio de la prensa. Aquí reaparece para De Angelis uno de los principales requisitos de una constitución justa: que reconozca el derecho irrestricto de libertad de imprenta. En efecto, en un artículo titulado "Ideas sobre la época presente", comienza haciendo un balance sobre los avances más notables que ha hecho la humanidad y señala como el más importante, en su opinión, a la igualdad en cuanto al estado intelectual que se ha producido entre los hombres.

Estos efectos [...] deben atribuirse a una fuerza de acción constante, enérgica, irresistible, que triunfa de todos los obstáculos, que perfecciona la razón humana, que ha abierto a todos los pueblos la carrera de las mejoras, que arrostra los vanos ataques de los enemigos de la libertad: tal es la imprenta, arte

${ }^{14}$ Ibid., p. 258. 
maravilloso que atraviesa los intervalos de tiempos y distancias y distribuye igualmente a todos los hombres los conocimientos más diversos [...] La imprenta dice al tirano: cesa de oprimir; y al hipócrita: no pretendas avasallarnos con tu perfidia [...] Pero desde que la imprenta hace circular todas las ideas, todos los ojos se han abierto. El número de los que observan es tan considerable que es imposible ocultar todos los crímenes. Los gobiernos no pueden ser injustos ni absurdos impunemente, a menos que sean lo bastante fuertes como para arrostrar la opinión, cometer impunemente el crimen y hacerse inaccesibles a la razón y a los remordimientos. La im. prenta no es solamente el órgano de la opinión pública; ella la protege, la defiende y debe considerarse como la porción más generosa del género humano. ${ }^{15}$

Pero De Angelis, quien cree que la libertad de imprenta debe ser irrestricta, también opina que quienes se desempeñen en la prensa política deben hacer uso moderado del lenguaje al publicar sus análisis de las leyes sancionadas y manifestar un vivo respeto por los funcionarios que eventualmente podrian ser criticados por medio de órganos periodísticos.

No hay libertad ni garantías sin esta publicidad. La delegación que hace el pueblo de su soberanía es temporaria y condicional; no es absoluta como en un gobierno despótico. El derecho de juzgar los actos de los hombres públicos es imprescindible en una democracia, y el que lo disputa o lo coarta desconoce el verdadero carácter de las instituciones republicanas. Lo único que puede exi-

15 Ibid., pp. 288-289. girse es que la discusión sobre los actos de una Asamblea deliberante sea imparcial e ilustrada. Añadiremos también que sea decente y respetuosa [...] como si una sociedad pudiera existir sin respetar a sus magistrados; que a más de esto son producto de nuestra voluntad y elección. Es muy natural que se traten con los miramientos que merecian como ciudadanos y a los que han adquirido nuevos derechos como representantes. Para que fuese lícito rehusárselos sería preciso probarles que se hicieron indignos de ellos por su conducta posterior, lo que no puede ser sino el resultado de un juicio público. La opinión de un solo individuo, y aun la de muchos, no puede hacer bajar a un elegido del pueblo del alto puesto a que lo han elevado la confianza y el aprecio de sus conciudadanos. Por más grande que sea el poder de la opinión pública en un régimen representativo, no debe ser ilimitado; sería reemplazar una tiranía por otra, más insoportable cuanto que no conocería más límites que los que le asignan las prevenciones, los caprichos y la malevolencia de la muchedumbre. ${ }^{16}$

Según esto, para De Angelis, así como la imprenta democratizó el conocimiento humano, la libertad de prensa, junto con la publicación de los actos de gobierno, pone a todos los hombres en igualdad de condiciones para la opinión política y por tanto para el ejercicio del poder en un sistema representativo. El tema del lenguaje reaparece: De Angelis sostiene que independientemente de que el juicio sobre el magistrado sea favorable o no, la forma de referirse a él debe ser tan

16 Ibid., p. 292. 
respetuosa como si se tratara de cualquier otro ciudadano.

Hemos dejado para el final, por considerarlos quizá los más importantes artículos publicados por De Angelis en su etapa de servicio a la causa unitaria, $a$ aquellos que aparecieron con el título de "Federales" y "Comparaciones políticas". En el primero, realiza una crítica de quienes rechazaron la Constitución de 1826; afirma que sería una carta admirable si en lugar de consagrar el principio de unidad hubieran consagrado el de federación. Cita las críticas que decían que ése era el único defecto que le encontraron y, a continuación, se pregunta qué constitución es la que no tiene ninguno y si es posible realizar en un primer intento un modelo de perfección. Recuerda también que con las críticas escritas sobre las constituciones vigentes en aquel entonces en Francia, Inglaterra y Estados Unidos podrían formarse bibliotecas enteras. Luego, ataca el único argumento que le ha parecido digno de atención, el que afirma que si Estados Unidos prospera bajo un sistema federal, en las Provincias Unidas deberían obtenerse los mismos resultados con los mismos medios.

¿No debe prosperar en un país lo que prospera en otro? No: por la misma razón que el bananero se cubre de frutos bajo el sol ardiente de los trópicos, y se seca en otra latitud; porque es imposible fundar una sociedad sobre un modelo dado como se edifica una casa según un plan convenido... ${ }^{17}$

17 Ibid., p. 267.
Más adelante da una razón más importante con la cual no sólo refuta la comparación, sino que critica también la actitud de los gobernadores federales frente a la guerra con Brasil.

Si reina ese convencimiento general en favor del federalismo, como un manantial de toda clase de venturas para la patria, trabajemos desde luego en liberarlo de sus enemigos, reunámonos en torno del gobierno para prodigarle todos los medios de defensa, después sobrará tiempo para discutir todas las formas posibles de gobierno [...] La cuestión de que se trata será prematura interin las provincias no hayan adquirido una existencia independiente: interin las pequeñas ciudades de San Luis, San Juan, Santa Fe, Santiago, La Rioja, ctc., no hayan llegado a ser tan grandes capitales como Boston, Nueva York, Baltimore y Filadelfia; ínterin por el desarrollo progresivo de la industria y el comercio hayan adquirido instrucción, riquezas y experiencia; ínterin sus recursos no se hayan puesto a la altura de sus deseos. Cuando todo esto se haya verificado, sí se podrá examinar despacio cuál de los dos sistemas es el mejor y se podrán emplear los medios legales para adoptarlo. Pero sembrar desconfianzas y discordias, fomentar revueltas para obtener la supresión de una frase; volver las armas contra los propios hermanos, cuando éstos las tienen esgrimidas contra el extranjero, son crímenes imperdonables a los ojos de la razón y apenas creíbles en el siglo actual. ${ }^{18}$

De Angelis parece acercarse a las ideas de Tocqueville al creer que, para la instauración de un sistema federal,

18 Ibid., pp. 267-268. 
es precisa la existencia previa de una sociedad compuesta por diversos polos de riqueza, educación, cultura política, etc., pero dada su ausencia pueden implantarse leyes que generen ese tipo de sociedad. Federalismo significa, según el autor, esta diversidad regional y no enfrentamientos civiles que sólo retrasan la constitución definitiva del sistema político. Pero no es aquí donde desarrolla mejor el concepto de federalismo y el gobierno que corresponde a tal sistema, sino en otro artículo de la misma época titulado "Comparaciones políticas". Ataca ciertos razonamientos -que hoy podrían ser calificados de simplistasmediante los cuales se pretende comparar a Estados Unidos con la Confederación. Ya habíamos adelantado que niega la factibilidad de esa comparación al asegurar que el análisis político y la investigación respecto a sociedades en su conjunto no son de ningún modo experimentales -es decir que las mismas causas no generan los mismos efectos en sociedades diferentes o que los mismos sistemas políticos no funcionan igual en países diversos-, sino que todo lo que sabemos acerca de estos temas son inducciones del pensamiento.

Así, afirma que es error común la comparación de pueblo a pueblo y de circunstancias a circunstancias; señala que diversas variables como clima, costumbres, historia, religión, antigüedad de la civilización, etc., se combinan en grados y formas diferentes dándonos el carácter de cada pueblo. Es imposible, según De Angelis, que todos estos elementos se combinen de igual manera en dos países, lo que los torna diferentes, $y$ por lo tanto manejarse en uno con la experiencia del otro es un error que puede producir -si aplicamos estas inferencias en el terreno político y social-consecuencias desastrosas.

A continuación ataca de lleno la comparación entre Estados Unidos y Río de la Plata:

Nada es tan cómodo a la pereza moral del hombre como resolvergrandes cuestiones con la ayuda de cuatro o cinco fundamentos. Los Estados Unidos están en América; nosotros también estamos en el misma parte del mundo; ellos se sacudieron el yugo de la metrópolis, nosotros hemos hecho lo mismo; ellos fundaron una república, nosotros hemos fundado otra; luego las circunstancias son las mismas y la regla de conducta debe ser la misma en aquel caso y en éste [...] La mayor parte de las personas que agitan en sus conversaciones negocios políticos, cuando hablan u oyen hablar de la condición de las colonias inglesas antes de su emancipación, se figura que cada una de ellas estaba gobernada por un virrey codicioso y feroz, sometidos a las sentencias semejantes de unos tribunales semejantes de un consejo como el de Indias y a las exacciones de una corte como la de Madrid.

Si se dijera a estos eternos comentadores de lo que no entienden, que las Provincias del Norte de América eran, bajo el yugo inglés, unas verdaderas repúblicas, quizá sacarían inducciones contrarias a las que hoy sirven de apoyo a sus delirios: porque al cabo, el influjo de las leyes y las costumbres es algo en la escala de las calidades nacionales y el pueblo que gime sumido bajo el despotismo más bárbaro y exterminador, ha de diferir en algo del que está en la an- 
tigua posesión de una libertad sólida y efectiva. Lo cierto es que cuando los americanos se declararon independientes, habían ya adquirido la mayor parte de los bienes que nosotros nos proponemos, y de ahí se infiere, que a nosotros resta andar el camino que ellos habían recorrido a la sazón. En posiciones tan diferentes, si más bien no deberían llamarse contrarias, sostener que deben ser iguales los rumbos que tome el cuerpo político, es un absurdo demasiado grosero para merecer una seria refutación. ${ }^{19}$

La cita nos parece clara. Muestra que De Angelis cree que la comparación entre Estados Unidos y Río de la Plata es imposible; a su juicio, una y otra sociedad no parten de una misma situación sino que lo hacen de situaciones tan diferentes que podrían llamarse opuestas y que, por tanto, querer dar un mismo régimen a dos pueblos cuya composición es tan diversa "es como pretender que los hombres lleguen a la sabiduría sin pasar por la enseñanza", ${ }^{20}$ En esta parte la coincidencia con Alexis de Tocqueville es profunda ya que, para ambos, Estados Unidos de Norteamérica tenía ya sólidas costumbres democráticas - a diferencia de las Provincias Unidas del Río de la Plata - cuando sancionó su Constitución. Luego, después de negar la similitud entre ambas sociedades, comienza a analizar la naturaleza del sistema federal con objeto de dejar en claro que pueden haber muchas formas de gobierno clasificables bajo ese concepto, incluidas algunas

19 Ibtd., pp. 276-277.

${ }^{20}$ Ibid., p. 279. que podrían ser opuestas entre sí. Afirma también que el federalismo no tiene un carácter fijo y determinado, sino que en cada país adquiere una forma peculiar y exclusiva.

Para convencerse de la verdad de este aserto es necesario tener presente que la voz federación sólo significa unión de sociedades y que según un texto muy respetable en esta materia "La extensión, las modificaciones, los objetos de la autoridad federal pueden combinarse y variarse discrecionalmente, sin pervertir la idea fundamental de federalismo".* Si hay reunión de cuerpos políticos, llámense estados, llámense provincias bajo una autoridad central y superior; si cada uno de estos estados o provincias nombra depositarios de su autoridad, y de su voluntad, para que cuide de su prosperidad y adelantamiento, existe indudablemente el régimen federal. "Poco importa, dice el mismo autor, que el gobierno nacional intervenga o no en los objetos de la administración interior; poco importa la igualdad o desigualdad de votos entre las diferentes provincias: todo esto es arbitrario y no puede decirse que haya principios, antecedentes, ni regla absoluta sobre el asunto".

A posteriori, critica a los opositores de la Constitución por escudarse en la autoridad de la Constitución norteamericana infiriendo ideas que, según De Angelis, no existían en la mente de sus autores, y comienza a examinar la importancia de la existencia de un gobierno central. Para esto vuelve a citar al general Hamilton:

* El general americano, Hamilton, en The Federalist. 
El gobierno debe dar a conocer su acción a los individuos y sin necesidad de legislaturas intermedias, debe tener el poder suficiente para hacer ejecutar sus resoluciones, por medio de los magistrados ordinarios. El gobierno de la Unión, como el de cada uno de los estados, ha de poder dirigirse inmediatamente a los temores, $y$ a las esperanzas de las personas, $y$ atraer en su apoyo las pasiones que más influyen en el corazón humano. Debe tener todos los recursos, y echar mano, para ejecutar el poder de que está revestido, de todos los medios que poseen y ejercen los gobiernos de los estados particulares. ${ }^{21}$

De Angelis utiliza aquí un recurso muy inteligente que es el de citar una autoridad en materia de federalismo para criticar y refutar a sus partidarios. De Hamilton extrae precisamente tres ideas: la primera de ellas es que el concepto de federación es absolutamente laxo, que no tiene un desarrollo doctrinario importante siendo asimilable al de reunión de sociedades.

Otra idea presente en la cita, derivada de la anterior, que De Angelis destaca, es que la organización interna de la federación surge de la que puedan y quieran darse los integrantes que la componen. Aquí la crítica a los partidarios de la federación argentina alcanza una cierta profundidad ya que éstos parecen identificar al sistema federativo con una determinada organización política; la cita de Hamilton que De Angelis presenta muestra que esto no necesariamente es así y que aun adoptando el sistema federal será imprescindible un debate posterior sobre la forma de gobierno.

${ }^{21}$ Ibid., p. 281.
Finalmente, una tercera noción que se desliza de lo expuesto es que debe haber un gobierno central con todos los poderes de los gobiernos de cada estado, $y$-esto es lo importante-que pueda apelar a los ciudadanos en forma directa. Aparece aquí la idea de un gobierno central que se superpone a los gobiernos de los estados en su capacidad de dirigirse a las personas en forma directa; así, la propuesta de De Angelis avanza hacia un concepto de tipo más federal alejándose de cualquier propuesta confederal que pudiera inferirse de la primera cita de $\mathrm{Ha}$ milton. 22

En abono de su pensamiento, De Angelis reproduce un texto aparecido en The American Review (núm. 1) en el cual puede leerse:

Ultimamente, la división del país en un cierto número de soberanías distintas, cada una de las cuales gozaba ya de un gobierno aparte, era una círcunstancia, que aunque retardaba la época del establecimiento de una Constitución general, favorecía en alto grado la perfección de su estructura. ${ }^{23}$

Con esto el autor reconoce, aunque no desarrolla, la existencia de la soberanía provincial. Ello no impide-como ya ha demostrado- la existencia de un gobierno central con los mismos poderes y atributos que los gobiernos particulares. Nuevamente hallamos en De Angelis una idea que años más

22 Para una definición precisa de ambos conceptos véase Chiaramonte, "Federalismo", 1993.

${ }^{23}$ De Angelis, citado en Trostiñé, Acusación, 1945, p. 278. 
tarde desarrollará Tocqueville mucho más profundamente y que parece ser el nudo del debate que asistimos en esta época en Río de la Plata. Acerca de las complicaciones que supone el establecimiento de una confederación, dice Tocqueville:

Entre los vicios inherentes a todo sistema federativo, el más visible es la complicación de medios que emplea. Este sistema enfrenta necesariamente dos soberanías. El legislador trata de hacer los movimientos entre estas dos soberanías lo más sencillos e iguales posible y puede delimitar a cada una su respectiva esfera de acción; lo que no puede hacer es que no haya más que una ni impedir que las dos se rocen en algún punto.

El sistema federativo se basa, pues, hágase lo que se haga, en una teoría complicada cuya aplicación exige de los gobernados el uso diario de la razón. ${ }^{24}$

\section{IDEAS POLITTICAS DE DE ANGELIS A}

\section{LA LLEGADA DE ROSAS AL PODER}

En la etapa en que De Angelis se pone al servicio del gobernador de la provincia de Buenos Aires, su labor, si bien sigue siendo periodística, adquiere un tono más bien publicitario dejando de lado el de analista político comprometido con las ideas unitarias, que caracteriza su etapa anterior. Son po$\cos$ los artículos en que aborda cuestiones doctrinarias sobre el Estado o el sistema político, y abundan, en cam-

${ }^{24}$ Tocqueville, Democracia, 1984, vol. I, cap. VII, p. 169. bio, los que defienden y publicitan las acciones del oficialismo.

En un artículo del Archivo Americano (octubre de 1846), cuyo objetivo es defender un decreto por el cual se constituye una comisión encargada de examinar las obras adoptadas para la enseñanza y la educación de la juventud, se introduce en el tema indicado la generosidad con la que ha actuado el gobierno al permitir abrir escuelas a todos aquellos que lo han solicitado. Describe como una atribución natural que el gobierno arbitre medios para evitar los males que pueden derivarse de una confianza ilimitada en el aspecto educativo. Así, afirma:

Este decreto no impone ninguna traba a los preceptores, que pueden seguir en sus cursos el método que consideren más adecuado; lo único que les prohibe es hacer uso de obras contrarias a los dogmas de la religión católica y del sistema político establecido en el país; es decir faltar a las obligaciones de cristiano y de argentino. Imposible sería exigir menos de los que desempeñan tan importantes funciones. Así como se prescribe a los farmacéuticos el no vender sustancias ponzoñosas, así también se inculca a los maestros de no enseñar lo que es inmoral o anárquico, porque el respeto de las leyes divinas y humanas es el fundamento de toda buena educación. 25

Más adelante, al aludir una crítica que seguramente recibió la resolución, responde:

25 De Angelis, citado en Trostiñé, Acusación, 1945, pp. 365-366. 


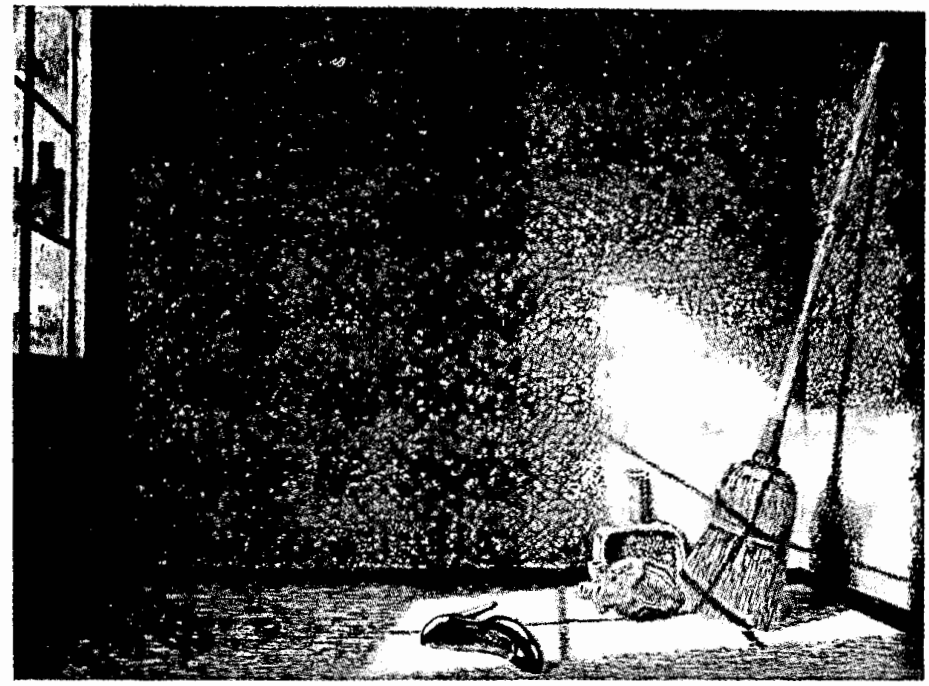

El mayor defecto que nota el salvaje unitario Varela en el decreto que examina, es el respeto que inculca al sistema politico del país, que él hace consistir en "un odio mortal a los enemigos del sistema". Pero, ¿no es un deber para todos, niños y adultos, de respetar y sostener el orden establecido? ${ }^{26}$

De Angelis parece mostrar aquí un cierto viraje ideológico respecto a lo escrito años antes. En efecto, en sus artículos analizados en el apartado anterior proponía la libertad de imprenta, el permanente debate político y la aceptación de una constítución que fijaría el sistema gubernativo pero que podría ser mejorada en virtud del trans-

${ }^{26}$ Ibid., p. 366. curso del tiempo y las críticas que pudieran hacerle los ciudadanos. En esa época, los magistrados eran sagrados y el sistema político debatible; ahora la federación parecía limitada por una comisión surgida de la Legislatura. No se pronuncia aquí por la intolerancia política -es más, parece estar polemizando con Varela- pero ahora hay temas que están fuera de toda posibilidad de examen, debate y cambio.

El argumento de fondo parece ser la necesidad de conservar las costum. bres de la sociedad. Si esto es así, nos hallamos ante una postura absolutamente diferente a la de su etapa anterior, ya que en ese momento su propuesta más clara era la de aceptar un sistema legal-perfectible, por supues- 
to- que generaría nuevas costumbres y hábitos en los hombres de la época.

Esos temas - la creación de un nuevo orden político, la introducción de pautas democráticas y la organización alcanzada por el Estado- son ampliamente desarrollados en un largo articulo publicado en el Archivo Americano en 1844. La nota es la respuesta a la visión de un viajero a quien no nombra y que ha volcado su parecer en la Revista de Dos Mundos. De Angelis hace un análisis pormenorizado y elogioso de la obra administrativa del gobierno de Rosas; incluye la regularización en la publicación de registros, sentencias judiciales, impulso a los estudios históricos, reorganización de la universidad, expedición al desierto, unificación de pesos y medidas, desarrollo alcanzado por la industria, la ciencia y las artes, etc., sin dejar de mencionar, por supuesto, que todo se ha hecho en medio de una tenaz guerra que los unitarios no abandonan.

Al abordar las opiniones que del sistema político imperante tiene el autor del artículo de la Revista de Dos Mundos, De Angelis afirma:

El viajero, al establecer que el sistema de terror oprime a Buenos Aires, adhiere con toda cordialidad a las absurdas acusaciones de nuestros enemigos. No existe, ni el general Rosas quiere o puede establecer, semejante terrorismo. El poder extraordinario que inviste por la ley, ha sido confirmado por el voto expreso de toda la provincia de Buenos Aires; y su encargo de dirigir las Relaciones Exteriores emana de la voluntad nacional auténticamente manifestada [...] Ni el general Rosas ni no- sotros hemos creado esta necesidad penosa. Nuestros enemigos con su incesante guerra, en que no han respetado principio alguno, ni el más leve sentimiento de humanidad, y la ingerencia de extranjeros crueles, empeñados en desolar nuestro país e imponernos una dominación que aborrecemos, nos ha obligado a prolongar en manos del más popular y capaz de nuestros compatriotas ese poder fuerte por la ley y por la voluntad. ${ }^{27}$

Esta defensa del gobierno de Rosas está revestida de la misma solidez doctrinaria que acostumbra a mostrar en todos sus escritos. Así, comienza negando que la existencia de un poder extraordinario sea sinónimo de instauración de un sistema político de terror y justifica el surgimiento de dicho poder merced a la guerra desatada por los opositores aliados a extranjeros que pretenden volver a oprimir al territorio. Pero el autor agrega, además, que el modo en que se ha instala. do el poder extraordinario ha seguido la vía del voto público, que es la manifestación de la voluntad nacional. En otras palabras, es legal porque ha sido propuesto por la Legislatura y aprobado por el voto de los ciudadanos, y es legítimo porque emana de la voluntad nacional.

Más adelante afirma que, en relación con el resto de las provincias,

No existe un solo cantón militar en las provincias del interior. Éstas gozan de su absoluta independencia, libertad, representación y derechos, de conformi-

27 De Angelis, Archivo Americano, 19461947 , p. 87. 
dad al tratado en que se funda la Confederación Argentina [...] El general Rosas no ha pertenecido jamás a club alguno. No tiene medios de coacción o de soborno. La fuerza de su gobierno está en la nación; sus títulos en la voluntad de ésta, sus recursos en la decisión $y$ voto de sus ciudadanos. ${ }^{28}$

Es interesante analizar en esta cita y la anterior la alusión que hace al concepto de nacionalidad, en el que se separan la ciudadanía de la provincia de Buenos Aires, por un lado, y la nación, por el otro. A la primera, la ciudadanía de la provincia, le otorga las facultades extraordinarias, mientras que a la nación-que se presenta como distinta y superior a Buenos Aires- le otorga la dirección de las Relaciones Exteriores. En la última cita, la idea se completa al explicitar el sistema político sobre el que se asienta la nación; una reunión de estados independientes y libres con representación y derechos conforme al tratado que funda la Confederación Argentina. Sin embargo, más adelante introduce la idea de que la nación puede tener distintos grados de desarrollo:

Volveremos al camino de que hemos estimado conveniente separarnos, cuando desaparezcan los graves peligros que amenazan a nuestra nacionalidad y en los que tiene no poca parte una fracción turbulenta de la sociedad extranjera que pugna en unión a los rebeldes por empujarnos hacia los tiempos bárbaros en que la fuerza brutal no atendía los derechos de la razón y de la libertad. Para arribar a nuestra naciona-

${ }^{28}$ Ibid., p. 87. lidad orgánica necesitamos del poder que hemos depositado en el general Rosas; es representante del sentimiento más caro y poderoso en pueblos que se estiman civilizados. ${ }^{29}$

Se ve claramente aquí cómo se introduce un agregado a la idea de nación y es que ésta puede ser, además, orgánica. Podría inferirse de las palabras de De Angelis que existe una nación cuya voluntad sostiene el encargo de las relaciones exteriores a Rosas y que se manifiesta a través de un régimen político de estados independientes, libres y unidos; pero que, asimismo, existe una nación orgánica, aún potencial, que en apariencia debería expresarse bajo otro sistema político. Para llegar a dicho sistema resultaría ineludible la existencia del gobierno de Rosas porque, según lo afirmado por el autor, éste frena las tendencias disolventes y pone en marcha una organización estatal burocrática imprescindible para la etapa posterior.

En un pasaje del mismo artículo, que se va publicando por etapas, el autor hace un balance de los efectos' sociales de la administración de Rosas y expone:

En el catálogo de causas que contribuyen al aumento de la población no conviene olvidar los progresos de las buenas costumbres que tanto han favorecido la administración del general Rosas persiguiendo la inmoralidad, el vicio y los desórdenes corruptores [...] Tanto trabaja en favor de la sociedad el que cultiva un campo como el que se corrige de un vicio. Esta tenden-

${ }^{29}$ Ibid., p. 88. 
cia favorece la libertad porque el hombre virtuoso es el que sabe amarla, que la comprende y la defiende. ${ }^{30}$

Páginas después, De Angelis asevera:

La Constitución de un Estado, para que sea sólido, debe provenir de la creación progresiva de instituciones análogas, de las costumbres radicadas en los pueblos, de la acción lenta pero segura del orden y de las leyes especiales de cada provincia. Hace ocho años que no dejamos las armas para repeler al bando rebelde unido a extranjeros enemigos de nuestra independencia, y una nación no se constituye en medio de una guerra. Pelea y salva su nacionalidad; después sigue naturalmente su Constitución. El gobierno del general Rosas, sosteniendo esas bases fundamentales sobre las que se ha de levantar la constitución nacional, es su más sincero amigo, el mismo poder extraordinario que ejerce por la voluntad pública, ha preparado en medio de la guerra, preliminares estimables que nos ha sido preciso señalar a la incuria del viajero. El tratado del 4 de enero de 1831 es la base de la Constitución de la República en que jamás pensaron los salvajes unitarios y que la ha establecido el general Rosas, aunque asediado del puñal de los facciosos. La organización política, administrativa y social de la provincia de Buenos Aires, la seguridad de sus fronteras, la morigeración de sus costumbres y tantos otros progresos del sistema liberal de orden y garantías, son otra base para la constitución del país, porque es inútil esperarla si sus provincias no llevan al todo nacional fracciones ordenadas y regulares. Los salvajes unitarios han conspirado contra ese

${ }^{30}$ lbid., p. 229. mismo tratado en que se apoya la nacionalidad argentina y que es la base de su constitución. ${ }^{31}$

Ahora resulta mâs inevitable que antes la comparación con el pensamiento expuesto por Tocqueville. Estamos en 1845. La democracia en América ya ha sido publicada en forma completa y sus traducciones circulan por el mundo; no sabemos si De Angelis ha tenido oportunidad de leer la obra, pero así como a fines de la década de 1820 encontramos que ambos autores tienen ideas en común -aunque Tocqueville las desarrollará en forma más precisa y profunda- ahora las coincidencias resultan más visibles aún. En efecto, el francés aborda en su obra el análisis de la sociedad y el sistema político de Estados Unidos y concluye que el estado social democrático permite un sistema político democrático y federal. Así, en orden de importancia, las costumbres, las leyes y los beneficios de un escenario geográfico adecuado posibilitan el surgimiento y mantenimiento de un estado social, a la vez que político democrático.

En los países donde las costumbres democráticas no tienen tradición, es decir aquellos que surgen de una tiranía, Tocqueville pensaba que las leyes podian y debían generar tales prácticas. A estas ideas se adhería De Angelis a fines de la década de 1820 , cuando proponía un sistema constitucional que creara ciudadanos habituados a la participación y control de los negocios públicos. Este era el diagnóstico y

${ }^{31}$ Ibid., p. 233. 
la solución que De Angelis impulsaba en aquel entonces: luego de varios años de gobierno rosista y como empleado a su servicio, el diagnóstico del problema -la ausencia de costumbres democráticas en pueblos que apenas han terminado de salir de una tiraníasigue siendo el mismo. El objetivo, la creación de una sociedad democrática y orgánica, también, pero han cambiado los medios propuestos. En efecto, ahora la solución impulsada se parece más a lo que Tocqueville descubría en el origen de las instituciones americanas: la existencia de una sociedad de costumbres virtuosas y moderadas, con hábitos republicanos. Así, Rosas es presentado como el gestor de una sociedad cuyas pautas de comportamiento permitirian, no bien se terminara la guerra con los enemigos del régimen, la sanción de una constitución. Esto mismo se hará en las demás provincias y las fracciones ordenadas y regulares constituirán más tarde un todo que es la nación argentina.

Así descubrimos que De Angelis cambia la dirección en que se construye la nación; mientras que en su etapa de servicio a las ideas unitarias militaba en favor de la creación de una nación y de un pueblo democrático vía la sanción de leyes destinadas a ese fin, en su etapa de servicio a Rosas propone la creación de una nación -permitasenos la expresión- "desde abajo", es decir, educando e imponiendo buenas costumbres a los hombres, y éstos se darán a sí mismos la organización nacional libre que tanto han buscado.

En cuanto al concepto de confederación, De Angelis lo expone en una polémica que mantiene con el perió- dico $E l$ Nacional de Montevideo en 1845. La disputa surge evidentemente por la cuestión de la libre navegación de los ríos, pero a colación se trae el tema de la independencia de Paraguay del resto de la Confederación, si existe, como debe darse y la naturaleza de los lazos que la ligan al resto de las Provincias Unidas. Seguramente, De Angelis adoptó aquí un concepto que le convenía para su postura sobre la navegación de los ríos, pero de todos modos éste no podría ser uno que no tuviera una cierta aceptación o una tradición intelectual detrás. En otras palabras, la idea de confederación que utiliza aquí el autor puede ser funcional a sus intereses puntuales respecto de la polémica que está sosteniendo, pero también creemos que es una idea más o menos difundida y aceptada, y no una creación ad hoc de De Angelis.

En estos tres artículos, con los que responde a $E l$ Nacional, el napolitano utiliza una profusa documentación y su objetivo es demostrar que "el gobierno argentino nunca pensó en quitar al Paraguay su.independencia, como el gobierno de Paraguay nunca tuvo la idea de separarse de la Confederación Argentina. ${ }^{32}$

Con esto intentó refutar la idea expresada por El Nacional, según la cual, Paraguay es un país independiente y separado de la Confederación. Así, afirma:

Ya hemos explicado lo que importa la palabra independencia, que El Nacional alega como una prueba evidente de la separación del Paraguay; siendo en

32 Ibid., p. 275. 
realidad el derecho de todo gobierno constituido, que no se pierde por adherirse a una liga, o confederación de estados. Este principio es tan inconcuso que se registra como axioma en las obras de los publicistas: "Muchos estados soberanos e independientes, dice uno de los más acreditados, puede juntarse en federación perpetua, sin dejar de ser cada uno en particular un estado perfecto. Formarán juntos una república federativa, pero sus deliberaciones comunes no atacan de ningún modo la soberanía de cada miembro, aunque lleguen a limitar su ejercicio en algunas circunstancias, por estipulaciones voluntarias. Un individuo no deja de ser libre e independiente cuando se obliga a llenar los compromisos que ha querido contraer. ${ }^{33}$

A continuación de la cita en que fijaba cuál es el concepto de república federativa -que según él expresa la organización imperante en el territorioDe Angelis sigue con una serie de citas documentales en las que la Junta Gubernativa Paraguaya manifestaba su voluntad de permanecer ligada a las Provincias Unidas. El surgimiento del doctor Francia en el escenario político paraguayo, quien implantó un reglamento de gobierno en el que determinaba las atribuciones de la nueva magistratura sin afirmar nada con respecto a las Provincias Unidas, no implica, en opinión de De Angelis, títulos positivos de la independencia de Paraguay:

La política tiene sus axiomas, como las ciencias, y uno de ellos es que las alianzas no se deshacen sin alegar los motivos del rompimiento. Además de que

${ }^{33}$ Ibid., p. 276. ¿dónde está la demanda de la independencia de Paraguay y el consentimiento del Gobierno o de los Congresos de las Provincias Argentinas que la otorgan? [...] ¿En qué difiere un pacto de unión entre los pueblos de lo que los juristas llaman contrato bilateral o sinalagmático? ¿No representan entrambos la promesa recíproca de las dos partes de cumplir fielmente lo pactado de respetar los derechos que se han trasmitido y de reivindicarlos cuando fuesen violados? Dos voluntades han concurrido para fundarlo, y dos voluntades se requieren para romperlo, y tan expresa debe ser la retractación como lo ha sido la promesa. ${ }^{34}$

Hasta aquí, el autor del artículo nos ha mostrado, tanto desde el punto de vista jurídico como político, cuál es la naturaleza del sistema que gobierna a las provincias argentinas y el modo en que surge y se impone. Se trata básicamente de gobiernos que forman una federación voluntaria en la que no pierden sus derechos soberanos particulares. El ingreso y egreso debe ser voluntario pero, además, explícito. El surgimiento de la dictadura del doctor Francia -alegada por El Nacional como una de las razones por las que Paraguay es independiente- no exime a dicha entidad de las obligaciones preexistentes.

Luego de aclarar el punto, pasa a explicar -y a defender-cuál es el papel del encargado de las relaciones exteriores.

Como encargado de las relaciones exteriores de la Confederación Argentina, no puede desmembrar su territorio, ni

${ }^{34}$ Ibid., p. 278. 


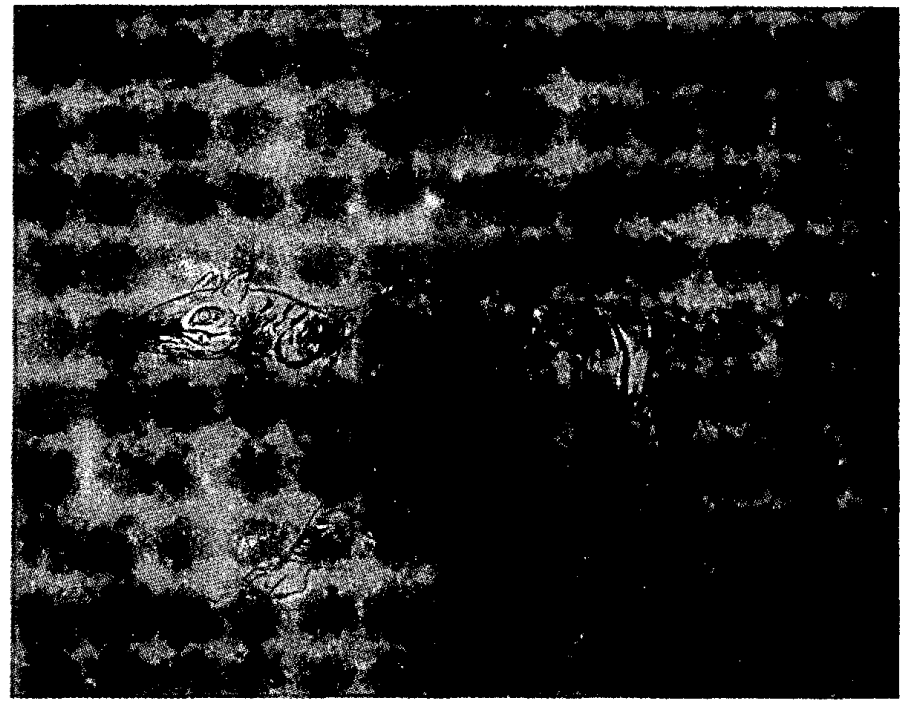

declarar independientes a los que no han cesado de ser sus partes integrantes. Este poder reside en el Congreso General de las Provincias Confedera. das, al que, si por algún tiempo han dejado de concurrir los diputados del Paraguay, no por esto han perdido el derecho de integrarlo. Son ellos los que deben promover la demanda de su independencia y exponer los motivos que tengan para solicitarla. ${ }^{35}$

Más allá de las posibilidades de los paraguayos para asistir al Congreso General de las Provincias Confederadas, que nunca fue convocado durante la etapa rosista, es interesante el concepto doctrinario, según el cual, no son los órganos ejecutivos -el en-

35 Ibid., p. 338. cargado de las relaciones exterioresquienes influyen en la integridad de la Confederación, sino un órgano colegiado, representativo y legislativo emanado de los estados que la componen. Ello guarda coherencia con lo que De Angelis expuso en los artículos con que respondió al viajero. En dichos artículos la nación surge de frag. mentos que, al alcanzar costumbres y prácticas democráticas a la par que desarrollo económico, pueden constituir una nación orgánica. Del mismo modo, la confederación, que sería la expresión política de la nación, es la suma de estados soberanos cuya máxima autoridad es el Congreso emanado de ellos mismos, y su poder ejecutivo es el encargado de las relaciones exteriores. 
IDEAS POLITTICAS DE DE ANGELIS DESPUÉS DE LA CAÍDA DE ROSAS

Luego del alejamiento de Rosas del poder, De Angelis no abandonó su papel de intelectual dedicado a cuestiones políticas. Aunque fue a Montevideo después de la batalla Caseros, en la que las fuerzas de Rosas fueron derrotadas por el general Urquiza, y más tarde a Río de Janeiro, donde ingresó al Real Instituto Histórico y Geográfico, se puso en contacto con el emperador Pedro II para regresar a Buenos Aires en 1854; pero, pese a estar en el extranjero, sus contactos con Urquiza fueron fluidos. La mayoría de sus cartas tratan de dos temas, el principal para De Angelis es la venta de su biblioteca -ya que está en la miseria- a Urquiza, y el otro es el envío de un proyecto de constitución de su autoría al Congreso Constituyente en 1852.

No es nuestra intención hacer aquí un análisis pormenorizado del proyecto de constitución redactado por De Angelis, pero sí pretendemos dar una visión global del mismo tratando de ver qué solución propone para el problema del federalismo. ${ }^{36}$

El texto constitucional se compone de ocho títulos a lo largo de los cuales se define el sistema político propuesto. En principio, resulta interesante la estructura interna que el autor da a su proyecto, ya que comienza reafirmando la independencia de la república y otorga la soberanía al pueblo que la

36 El texto completo del proyecto de constitución de De Angelis fue publicado por Ravig. nani, "Asambleas Constituyentes", Historia, vol. vl, 1937, pp. 763-770. ejerce por medio de delegados, y fija los límites fronterizos, la religión del Estado y los derechos y obligaciones de los ciudadanos.

En el segundo título fija la forma de gobierno como republicana y federal, luego de lo cual hace una lista de las provincias que componen la federación. En el título siguiente define la división de los poderes del Estado y sus atribuciones; establece un poder legisiativo, un ejecutivo y un judicial. Comienza describiendo las características y funciones del legislativo y sigue con las de los otros dos poderes. A continuación, en el título vII, fija reglas de administración, deberes y derechos de las provincias, dejando para el título VIII los mecanismos para ejecutar, interpretar y reformar la Constitución.

Esta estructura del texto nos adelanta que De Angelis hace primero una definición del escenario político y de los actores para pasar luego a fijar las reglas de juego entre ellos. Así, cuando se refiere al territorio de la república afirma que se compone del antiguo virreinato con excepción de la República de Bolivia y la de Uruguay. Con Paraguay propone que, luego de jurada la Constitución, se restablezcan las relaciones encargándose de las negociaciones al Congreso Nacional, que hará también las reclamaciones correspondientes para hacer valer los derechos sobre Tarija, Malvinas y estrecho de Magallanes. La determinación de las fronteras con los países limítrofes deberá quedar a cargo del ejecutivo nacional.

Establece la religión católica apostólica y romana como la oficial y a la 


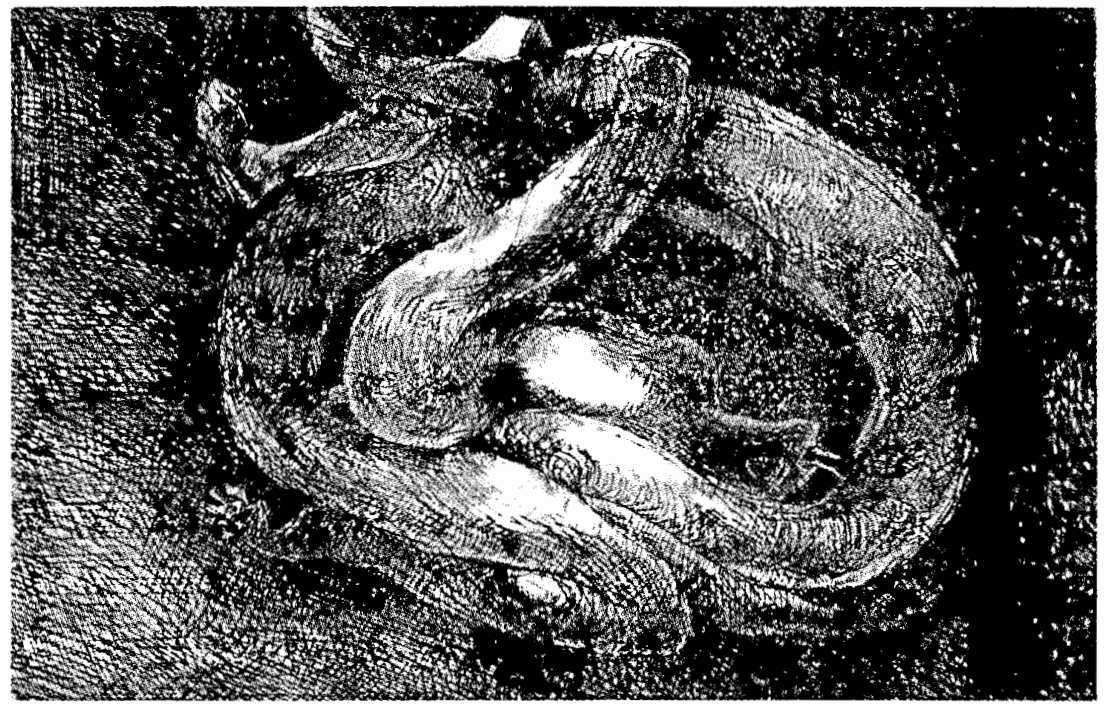

que el Estado brindará protección. Posteriormente, establece la tolerancia religiosa, que no alcanza el grado de libertad de cultos, y legisla sobre las relaciones con la Santa Sede, que deberán ser cordiales mientras se respeten las prerrogativas nacionales.

En la sección cuarta define quiénes son ciudadanos: " 11 . Son argentinos todos los que han nacido o nacieren en el territorio de la República." 37

Establecía en artículos posteriores que también serían argentinos los hijos de extranjeros avecindados en el país y de los argentinos que nacieran en el extranjero. Asimismo, se afirmaba la igualdad ante la ley, la obligación de defender al Estado y la abolición de

37 Ibid., p. 764. la esclavitud. En el artículo 16 fijaba las causas por las cuales se perdería y por las cuales se suspendería la calidad de ciudadano; entre las primeras incluyó la desnaturalización en otro país, ser empleado de otro gobierno, quiebra fraudulenta, etc. Se suspendería también por hábitos de ebriedad, por hallarse procesado criminalmente, por ser deudor insolvente del Estado y obviamente por interdicción judicial.

En el Título II, abordó el problema de la forma de gobierno y de las partes que integrarían la república.

19. La República Argentina adopta para su gobierno la forma republicana, representativa y federal.

20. Las provincias que componen esta federación son la provincia de Bue- 
nos Aires, Pcia. de Santa Fe, Pcia. de Entre Ríos, Pcia. de Corrientes, Pcia. de Córdoba, Pcia. de Santiago del Estero, Pcia. de Catamarca, Pcia. de Tucumán, Pcia. de Salta, Pcia. de Jujuy, Pcia. de La Rioja, Pcia. de San Juan, Pcia. de Mendoza, Pcia. de San Luis.

21. Todas ellas, en su administración interior, dependen de sus magistrados, sin más trabas que las que le oponen los principios constitutivos de la República y los deberes comunes a los estados que la forman. ${ }^{38}$

En estos tres artículos, De Angelis fijaba el sistema político y sus alcances, inclinándose por el federalismo y reafirmándolo en el artículo 21 , según el cual las provincias conservarian su autonomía limitada sólo por los deberes comunes a todas ellas.

Bajo el Título III definía la división, composición y atribuciones de los poderes del Estado, para lo cual previó la delegación de la soberanía de la nación en un poder legislativo, un ejecutivo y otro judicial; mientras que en el título siguiente describió al poder legislativo compuesto de dos cámaras, una de diputados y otra de senadores. La Cámara de Diputados se integraría con los representantes de las provincias elegidos por los ciudadanos de cada una de ellas, con base en un censo a realizarse cada diez años. Cada provincia enviaría un número distinto de diputados según la proporción que determine el mismo Congreso. En el artículo 32, dispuso que la calidad de los electores y el modo de proceder a la elección lo fijaría cada legislatura provincial.

${ }^{38}$ Ibid.
La Cámara de Senadores se compondría de dos representantes por provincia elegidos por las diferentes legislaturas, y los requisitos para ser tanto diputado como senador serian los mismos. Entre las funciones del Congreso están la de gestionar proyectos de leyes -señalada en último lugar-y entender en acusaciones contra el presi. dente de la república en delitos de traición contra la independencia o contra la forma de gobierno, por impedir la realización de elecciones y dificultar a las cámaras el uso de sus atribuciones constitucionales. Estas facultades se extienden también en el caso de que los acusados sean los miembros de la Corte Suprema o gobernadores de provincia, en cuyo caso serán

por infracción de la Constitución, o falta de cumplimiento de órdenes del presidente de la república, que no sean evidentemente contrarias a las leyes que la rigen; y también por la publicación de leyes y decretos opuestos a la misma Constitución. ${ }^{39}$

Entre las atribuciones y obligaciones del Congreso figuran las de mantener la independencia nacional, proveer a la seguridad y dignidad de la nación en sus relaciones exteriores y afianzar la unión federal, la paz y el orden público en la república. En esta secciôn también señala: "3. Mantener la independencia de las provincias en su régimen anterior con arreglo a la presente Constitución".40

En los siguientes artículos incluye:

39 Ibid., p. 765.

${ }^{40} \mathrm{Ibtd}$. 
9. Autorizar al presidente del Estado para declarar la guerra, en vista de los datos que presente.

10. Designar la fuerza armada de mar y de tierra, sobre los informes del presidente de la república, y fijar el contingente de cada provincia.

17. Determinar la parte que cada provincia debe tomar en el gasto nacional. ${ }^{41}$

En cuanto a la formación de leyes estipula:

48. La formación de leyes pertenece exclusivamente al Congreso. Sus proyectos pueden ser introducidos indistintamente en una o en la otra Cámara; excepto las que versan sobre contribuciones o impuestos, que no pueden iniciarse sino en la Cámara de Diputados.

49. Se tendrán como iniciativas de leyes y decretos. 1. Las posiciones del presidente de la república. 2. Las demandas o proyectos de leyes y decretos que las legislaturas provinciales dirijan a cualquiera de las dos cámaras. 3 . Y las proposiciones que presenten sus miembros...

56. Las leyes y decretos se modifican y abrogan con las mismas formalidades, y por los mismos trámites con que se establecen. ${ }^{42}$

En otros artículos de la misma sección se establecía que la duración de cada legislatura nacional sería de tres años, con una renovación parcial de un tercio de sus miembros. Asimismo, determinó que las sesiones ordinarias duraran desde el 9 de julio al 10 de noviembre de cada año. Durante el lapso restante se reuniría una comi-

41 Ibid.

42 Ibid., pp. $765-766$. sión permanente de dos senadores, tres diputados y un suplente para cada cámara. Sus atribuciones serían:

1. Velar sobre la observancia de la Constitución y de las leyes fundamentales del Estado, para dar cuenta al siguiente Congreso de las infracciones que pueden haberse cometido.

2. Convocar el Congreso a sesión extraordinaria en los casos previstos por la Constitución. 43

A continuación, bajo el título IV, presenta el articulado que organizó al poder ejecutivo. Establece un ejecutivo depositado en el presidente de la república argentina, secundado por un vicepresidente que lo reemplazará en caso de impedimento físico o moral. El artículo 70 dispone: " 70 . El vicepresidente de la Confederación será el gobernador y capitán general de la provincia de Buenos Aires". 44

Asimismo, se fija como residencia de ambos jefes la ciudad de Buenos Aires y dos comisiones, una del Congreso y otra de la Legislatura porteña, que dictarán un reglamento que deslinde las atribuciones de ambas autoridades para evitar conflictos jurisdiccionales. La elección de presidente será por medio de las legislaturas provinciales, que enviarán en sobre cerrado dos nombres al Congreso; quien obtenga la mayoría de votos será proclamado presidente. El cargo dura cuatro años y se podrá ser reelecto por única vez con las dos terceras partes de los votos de las legislaturas provinciales.

\footnotetext{
43 Ibid., p. 767.

${ }^{44}$ Ibid.
} 
Entre las atribuciones del presidente figuran la suspensión de leyes que deberán ser enviadas dentro de los diez primeros días, con las observaciones correspondientes, al Congreso; reglamentar las leyes que éste expida y cuidar la administración de justicia sin atacar la independencia de los magistrados. Más adelante, se establece:

9. Es el comandante en jefe de todas las fuerzas del Estado y tiene bajo sus órdenes los cuerpos de línea, las milicias, y la Marina Nacional, para proteger la seguridad y tranquilidad de la república y la libertad civil de los ciudadanos.

10. Disponer de la fuerza armada permanente de mar y tierra y la milicia activa para la seguridad interior y la defensa exterior del Estado.

15. Dirigir negociaciones diplomáticas y estipular tratados de paz, amistad, tregua, neutralidad, comercio, alianza o cualesquiera otros, sometiéndolos antes de ratificarlos, a la aprobación del Congreso.

17. Acordar el pase, o retener los breves y bulas pontificias, cuando contienen disposiciones contrarias a las prerrogativas nacionales; dando cuenta al Congreso de los motivos que ha tenido para hacerlo. ${ }^{45}$

A continuación, el proyecto de Constitución fija prohibiciones para el poder ejecutivo.

1. Ausentarse del territorio de la república sin permiso del Congreso.

2. Mandar en persona las fuerzas de tierra y mar sin el mismo requisito.

3. Impedir la reunión regular del Congreso o estorbar sus trabajos.

$45 \mathrm{Ibid}$, p. 768.
4. Celebrar tratados de cualquier especie, sin someterlos después a la aprobación del Congreso.

5. Enajenar, ceder o permutar ninguna parte del territorio argentino.

8. Imponer contribuciones o aumentarlas sin consentimiento del Congreso. ${ }^{46}$

En otra parte se establece un gabinete de cuatro ministros que ayudarán al presidente de la república:

92. Para el despacho de los negocios del gobierno habrá cuatro ministros o secretarios de Estado a saber:

Un ministro de Relaciones Exteriores, encargado también de las relaciones con las demás provincias de la República.

Un ministro de Gobierno.

Un ministro de Hacienda.

Un ministro de Guerra y Marina. ${ }^{47}$

Sus atribuciones serán determinadas por una ley especial, pero tienen la obligación, establecida por el artículo 96 , de presentar cada uno una memoria circunstanciada de los asuntos de su área al Congreso cada vez que éste comience sus sesiones ordinarias.

El título VI instituye un poder judicial encabezado por una Suprema Corte compuesta por nueve miembros que surgirán de ternas presentadas por las legislaturas provinciales y elegidos por el Congreso. Sus atribuciones son conocer en las causas que determinen la suspensión del presidente, vicepresidente o gobernado-

46 Ibid.

47 Ibid. 
res, en las causas promovidas contra diputados o senadores y de las infracciones a la Constitución. También tendrá jurisdicción cuando se suscite competencia entre provincias y resolverán sobre contratos celebrados por el gobierno y sus agentes. Asimismo, quedan abolidos los fueros, se establece la inviolabilidad del domicilio, el derecho de habeas corpus y el principio de que todo individuo es inocente hasta que se demuestre lo contrario.

A continuación, bajo el título vi, se describen las obligaciones de las provincias.

130. Las provincias continuarán administrándose según sus propias leyes; pero para uniformar en lo posible su organización, el Congreso se ocupará de un plan general, que será sometido a las legislaturas provinciales.

131. Las provincias de la república están obligadas: 1. A no poner trabas a la presente Constitución después de haber sido jurada. 2 . A cumplir y hacer cumplir las disposiciones del Congreso, y a ejecutar los tratados hechos, y que adelante se hicieren por la autoridad suprema de la república. 4. A entregarse mutuamente criminales cuando sean reclamados por el gobierno de la provincia a que pertenecen. 5 . A contribuir en proporción de su población y de sus recursos a la defensa del Estado, gastos de guerra, a la consolidación y amortización de la deuda nacional reconocida por el Congreso.

132. Ninguna provincia podrá: 1. Establecerse o fraccionarse sin consentimiento del Congreso. 2. Entrar en relación con ninguna potencia extranjera ni declararle la guerra $[\ldots]$ 3. Establecer peajes por el tránsito de los carruajes, hombres y animales de otras provin- cias, excepto en caso de construcción de puentes, o de otras obras, para facilitarlo, lo que hará con autorización del Congreso. ${ }^{48}$

En este bosquejo que hemos hecho sobre el proyecto de constitución enviado por De Angelis a las autoridades de la Confederación en 1852, podemos ver hacia dónde se encaminaban sus propuestas políticas en la última etapa de su actuación. El proyecto intenta dar solución constitucional a problemas políticos de larga data, como el asiento de las autoridades, límites, provincias que componen la Confederación y las relaciones entre la provincia de Buenos Aires y el resto de las provincias. En cuanto a su contenido habíamos dicho que la estructura del texto adelanta algunas de sus ideas.

En efecto, si nos concentramos en la forma y composición del gobierno que propone para la Confederación, notamos que define antes las funciones y atribuciones del Congreso que las del poder ejecutivo. Si pasamos a analizar las atribuciones de cada uno, surge inmediatamente que el órgano de máximo poder en la Confederación es, sin duda, el Congreso, que subordina al ejecutivo para que ponga en ejecución las leyes. Así por ejemplo, el ejecutivo no puede legislar ni decretar, sólo hacer posiciones que el Congreso debate y sanciona.

Del mismo modo, el gabinete debe rendir cuentas al Congreso al comienzo de cada periodo de sesiones ordinarias y debe hacerse responsable de los actos que autorice. También puede

${ }^{48}$ Ibid., pp. 769-770. 
verse que el presidente, quien si bien es el comandante en jefe de las Fuerzas de Tierra y Mar, no puede mandarlas en persona sin la autorización del poder legislativo. Finalmente, si nos detenemos a examinar el mecanismo de elección del presidente, encontramos que ésta se realiza en el Congreso mediante una votación de las legislaturas provinciales realizada previamente.

En cuanto a las cámaras, notamos que la de Diputados emana de la votación directa de los ciudadanos, y la de Senadores de las elecciones que se hacen en las legislaturas, que también proponen a los miembros de la Corte Suprema aunque éstos son elegidos por el Congreso; si a eso agregamos que en el artículo 130 se asegura la autonomía de las provincias, no resulta dificil comprender que De Angelis propone un Estado de provincias autónomas, regidas por un poder colegiado -el Congreso- que tiene como ejecutor de sus leyes al presidente de la república, quien no tiene la atribución de dictar leyes ni decretos.

Resulta un tanto difícil medir el grado de autonomía de cada estado provincial, ya que si bien en el artículo 130 se reafirma esta condición cuyo garante es el Congreso, en el 131 inciso 2 se sanciona la obligatoriedad de obedecer las leyes emanadas del mismo. Las provincias parecen no tener más poder sobre las cámaras que el que les otorga la posibilidad de elegir a sus miembros, con lo cual, el único modo de evitar los roces de las soberanías particulares con la soberanía nacional es la negociación política en el seno del Congreso. Esto le otorga al sistema una cierta flexibilidad que parece tender hacia el centralismo -hacia el federalismo, según algunos autores-, ${ }^{49}$ si tenemos en cuenta que es el Congreso el escenario donde se dirimen esas diferencias. Es importante recordar que hay también una jerarquización de las provincias ya que éstas participan en la Cámara de Dipu. tados según la cantidad de habitantes -según el desarrollo, podría decirseque hayan alcanzado y que contribuyen a los gastos del Estado en proporción a sus recursos.

Parece claro que De Angelis sigue fiel a las ideas que impulsó durante su etapa de servicio a Rosas, en las que el sistema político se construye desde abajo hacia arriba, desde lo particular a lo general, pero en el cual, luego de instalado, se impone un cierto centralismo ejercido por el Congreso.

Es interesante notar que las referencias al concepto de nación son escasas; el presidente lo es de la república, el Congreso no se llama nacional y los ciudadanos lo son de la república, no de la nación. Solo el poder judicial es nacional e interviene en las cuestiones de la república cuando el Congreso determina que hay un posible delito cometido por los representantes y agentes del Estado.

\section{CONCLUSIONES}

A lo largo de este trabajo hemos tratado de dar una visión general de las ideas de Pedro De Angelis. Si nos guiamos por el contenido de su produc-

${ }^{49}$ Chiaramonte, "Federalismo", 1993. 
ción intelectual, podriamos dividir su pensamiento en dos etapas a pesar de que su actividad política pasó por tres: la unitaria, la rosista y la posrosista.

En la primera etapa intelectual De Angelis sigue los lineamientos típicamente unitarios heredados del iluminismo borbónico. En efecto, en esta época se muestra partidario de las ideas que proponían la edificación de un sistema político que organizara a la sociedad según determinados valores y principios. De este modo, el Estado, producto de dicho sistema político, impone los objetivos que guían a la sociedad, a la vez que controla el proceso destinado a la obtención de los mencionados fines. Es un sistema de ideas que impulsa la creación "desde arriba" de un orden social y político por una elite letrada que -a falta de ciudadanos habituados al manejo de los negocios públicos- fija las reglas del juego. Este orden se democratizará al generar hombres comprometidos con él y se posibilitará así su incorporación a la toma de decisiones. Esta "república posible" dará paso, con el transcurso del tiempo, a la "república verdadera", tal como propondrá Alberdi años más tarde en sus Bases. ${ }^{50}$

En su segunda etapa intelectual, De Angelis muestra un viraje ideológico profundo. Ahora puede verse una coherencia más estrecha con lo manifestado por Rosas en su famosa carta a Quiroga fechada en la Hacienda de Figueroa el 20 de diciembre de 1834 -y a la cual cita en alguna oportuni-

${ }^{50}$ Alberdi, Bases, 1966, pp. 52-55. dad-que va a mantener luego de la batalla de Caseros. En esta época sostiene que la creación del orden político y social debe darse "desde abajo" en un doble sentido. Por un lado, asegura que serán los ciudadanos quienes mediante la participación política construirán al Estado, y no a la inversa. Por otro, este "desde abajo" significa que el nuevo orden surge de lo particular a lo general, de lo regional a lo nacional. De este modo, justifica el orden rosista - que ha tenido la virtud de crear a estos ciudadanos que no existían debido a las características del sistema colonial español- y propone un flexible sistema federal que permite el acomodamiento y la coexistencia de las soberanías provinciales junto a la nacional y cuyas competencias se resolverán a través del debate político en el Congreso de la república.

No descartamos que, además de Rosas y el ejemplo norteamericano, también haya influido en De Angelis la obra de Alexis de Tocqueville, ya que los remedios que propone en esta etapa son los mismos que el francés descubre que se han dado los americanos del norte, tal como hemos podido ver.

Nos resulta muy llamativo que las propuestas de De Angelis en su segunda etapa parezcan diametralmente opuestas a las que expresa Alberdi en sus Bases. ${ }^{51}$ En efecto, mientras que Alberdi impulsa -según las palabras de Halperín Donghi-52 una solución autoritaria progresista en la que el sistema político disciplina a las diversas elites locales y a los ciudadanos, De

51 Ibid.

${ }^{52}$ Halperín, Nación, 1982, pp. 37 y ss. 
Angelis propone un sistema consensuado por dichas elites mediante su participación en el Congreso nacional y a las que les reserva una amplia esfera de poder en sus respectivos espacios regionales. De este modo, las instituciones dominantes, en la propuesta del napolitano, son antes las provincias y el Parlamento que el poder ejecutivo.

Evidentemente, el proyecto de Constitución de De Angelis cayó en el olvido no sólo por el desprestigio político de su autor, que la mayoría de los historiadores destaca, sino porque además iba en contra de las tendencias ideológicas dominantes en el país en ese momento, ya que los proyectos debatidos en el Congreso Constituyente de 1852 tienen características que los acercan más a los regímenes presidencialistas -dado que le otorgan al poder ejecutivo la facultad de legislar en ciertos casos y de intervenir en las provincias- que a aquellos de tipo parlamentarista, como el que impulsa De Angelis.

\section{BIBLIOGRAFIA}

-Alberdi, Juan Bautista, Bases y puntos de partida para la organización política de la República Argentina, Buenos Aires, 1966.

-Busaniche, J.L., Rosas visto por sus contemporáneos, Buenos Aires, 1955. to federal, Buenos Aires, 1931. ,Formación histórica delpac-

-Beltrán, O., Historia del periodismo argentino, Buenos Aires, 1943.

-Carmagnani, M. (comp.), Federalismos latinoamericanos, Fondo de Cultura Económica, México, 1993.

-Crescent, Joseph, "Argentine constitutional history: A reexamination", HAHR, núm. 51, 1961.

-Chiapperini, Julio, Bibliografia sobre Rosas, Rosario, 1973.

-De Angelis, Pedro, Archivo americano y espiritu de la prensa del mundo, Buenos Aires, 1946-47.

-Díaz Malone, Vida y obra de P. De Angelis, Santa Fe, 1968.

-Galván Moreno, C., El periodismo argentino, Editorial Claridad, Buenos Aires, 1942.

-Halperín Donghi, $T$., Una nación para el desierto argentino, CEAL, Buenos Aires, 1982.

"Historia argentina de la revolución de independencia a la Confederación Rosista", Buenos Aires, 1989.

-Irazusta, Julio, "Pedro de Angelis, vocero de Rosas", Estudios Americanos, vol. 9, núm. 44, Sevilla, 1952.

-Marco, Carlos, Don Juan Manuel de Rosas. Sus detractores y sus panegiristas, Mendoza, 1953.

-Mansilla, L. V., Rosas, Buenos Aires, 1968.

-Ramos Mejía, J. M., Rosas y su tiempo, OCE, Buenos Aires, 1944.

-Ravignani, E., Historia constitucional argentina, Buenos Aires, 1937.

-Rodó,J. E., La tradición intelectual argentina, Buenos Aires, s/a.

-Rojas, Ricardo, Historia de la literatura argentina, Buenos Aires, 1960.

-Saldías, A., La evolución republicana durante la revolución argentina, Madrid, 1919.

-Tocqueville, Alexis, La democracia en América, Sarpe, Madrid, 1984.

-Trostiñé, R., Acusación y defensa de Rosas, Buenos Aires, 1946.

-Zinny, Antonio, La Gaceta Mercantil de Buenos Aires, Buenos Aires, 1869. 